УДК 82.01

DOI: $10.17223 / 23062061 / 16 / 5$

\title{
Н.В. Отургашева
}

\section{КНИГА КАК ПРОСТРАНСТВО ОБРАЗОВ И СМЫСЛОВ: КРУГ ЧТЕНИЯ СОВРЕМЕННОЙ СТУДЕНЧЕСКОЙ МОЛОДЕЖИ}

Аннотация. $B$ статье представлены результаты опросов и лингвистических экспериментов, проведенных автором в 2015-2017 г2. среди российских и тайваньских студентов, а также китайских и монгольских школьников. Целью исследования являются выяснение отношения современной молодежи к лингвокультурному конщепту «книга», определение круга актуальных для молодых читателей произведений художественной литературы и типов читательского восприятия, оченка роли книги в формировании персоносферы студенческой молодежи.

Ключевые слова: лингвистический эксперимент, лингвокультурный концепт, книга, читательское восприятие, культурный код.

Многочисленные дискуссии о месте литературы в школьном образовании, о роли книги и статусе писателя в современном российском обществе свидетельствуют о серьезных изменениях в самой структуре национальной культуры, ядром которой являлась великая русская литература.

Литературоцентричность русской культуры, то особое символическое значение, которым наделено было художественное слово для образованного российского, а затем и советского читателя, вполне соответствовали той «предельно высокой значимости» книги, которая, по мысли Б.В. Дубина, «сопровождает практически всю историю секулярной книжной культуры, больше того является принципиальным компонентом конструкции этой культуры и даже ее движущим механизмом» [1].

Герои литературных произведений, наряду с реальными историческими деятелями и фольклорными персонажами, населяют символическое пространство национальной персоносферы [2] и формируют вполне реальные социально-коммуникативные модели 
поведения и нравственно-этические представления лингвокультурного сообщества.

Однако в эпоху общественных переломов, когда происходят разрушение традиционных ценностных систем и деформация соответствующих им социальных институтов, наступает та ситуация духовной неопределенности, которая приводит к рассогласованию ценностей и образцов, декларируемых разными «сигнальными» системами, существующими в обществе. В отношении литературы такой разлад приводит к предсказуемым последствиям: происходит «разрыв образованного сообщества или, вернее, определенных, “прежних" его фракций с современностью как горизонтом актуальной (неотложной) коммуникации», меняются состав и качество читательской аудитории, списки хрестоматийных текстов литературы подвергаются ревизии, а «классика, декларативно представляемая в нормативных поэтиках и традиционалистских манифестах обобщенным образцом устойчивости в изменении», лишается «какой бы то ни было смысловой однозначности» [3].

Интерес к проблеме читателя в современных гуманитарных исследованиях имеет серьезные и веские основания. По мысли В.В. Прозорова, именно «читатель помогает понять литературный процесс во всей его неискаженной целостности». Книга для читателя пишется, им воспринимается и осмысляется, она остается в общественном сознании и памяти нескольких поколений именно потому, что созданный писателем художественный мир отвечает насущным духовным потребностям социума. «Читатель» и «чтение» - это единство, вне которого невозможно извлечение информации, содержащейся в любом текстовом сообщении» [4. С. 232].

Особенно актуальной проблема «книга - чтение - читатель» становится в эпоху социальных потрясений и перемен, когда рушатся былые идеалы и низвергаются прежние авторитеты, а люди, нуждаясь в духовной опоре, обращаются к печатному слову, художественной литературе - в надежде найти там ответы на самые злободневные вопросы насущного бытия.

Очевидно, что книга порождается эпохой, литературные сюжеты и образы «вызревают» в недрах своего времени и открываются 
читателю в контексте определенных социокультурных обстоятельств, поэтому «привлекательность книги часто напрямую зависит от того, насколько ее содержание совпадает с интересами и потребностями читателей в данный период времени» [5. С. 163]. В разных сферах научного знания утвердились различные аспекты изучения читателя: «Социологов, педагогов, книговедов занимает человек с книгой в руках, его запросы, интересы, потребности; филолога влечет к себе книга в руках человека, внутренние “готовности” произведения к воздействию на читателя» [4. С. 239].

В настоящей статье предпринята попытка анализа читательский предпочтений студенческой молодежи, вчерашних старшеклассников, освоивших школьный курс литературы и вступивших сегодня на путь самостоятельного выбора книг. Каков круг чтения современных студентов, под влиянием каких факторов он сформировался, каковы герменевтические способности молодых читателей, каково их отношение к книге как важнейшему феномену национальной культуры вот вопросы, которые интересовали автора.

В статье представлены результаты опросов и социолингвистических экспериментов, проведенных в 2015-2017 гг.: в них приняли участие российские студенты Сибирского института управления - филиала Российской академии народного хозяйства и государственной службы при Президенте Российской Федерации (всего 230 человек), студенты из Тайваня, изучающие русский язык в Национальном Тайваньском университете и Государственном университете Чженьчжи на факультете славистики (всего 20 человек), китайские и монгольские школьники, приступившие к изучению русского языка (всего 46 человек).

Цель исследования - выяснить отношение современной молодежи к лингвокультурному концепту «книга», определить круг актуальных для молодых читателей произведений художественной литературы, очертить типы читательского восприятия и оценить роль книги в формировании персоносферы студенческой молодежи.

В ходе свободно-ассоциативного эксперимента его участники заполняли опросный лист, в котором записывали свои ассоциации и приводили определения к слову-стимулу «книга», а также отве- 
чали на поставленные вопросы. Анализ полученных результатов составил содержание данной статьи и позволил сделать следующие выводы (ответы студентов при прямом цитировании передаются курсивом, при необходимости в скобках указывается количество полученных ответов в процентном соотношении к общему числу участников опроса).

Несмотря на то что сегодня книга потеснена другими формами досуга и, прежде всего, телевидением и Интернетом, она продолжает сохранять для студенческой молодежи высокую значимость и актуальность: 94\% респондентов считают чтение необходимостью для современного человека (обязательно, несомненно, это способствует формированию личности). При этом 70\% молодых людей читают художественную литературу регулярно, 7\% - ежедневно и только 1\% опрошенных не читают никогда. Чтение печатных книг предпочитают 72\% участников опроса, электронных $18 \%$, а $10 \%$ читают и те, и другие, не придавая особого значения формату представленного текста.

Книга в сознании российских студентов связана с областью знаний и размышлений, с образовательным пространством, в котором они существуют. Среди определений книги доминируют прилагательные, характеризующие степень увлеченности самим процессом чтения: интересная, увлекательная, захватывающая, интригующая. Довольно часто позитивно окрашенные определения переносятся на самого читателя, и он предстает перед нами как «начитаннылй, умнылй, эрудированный, воспитанный, интеллектуальный, образованный». Процесс чтения книги осознается как необходимое условие становления развитой современной личности.

Для тайваньских студентов книга - и в рамках традиции, и в контексте актуальной для них деятельности - понятие значимое и наделенное позитивным смыслом: оно связано со знанием, мудростью, философией, чтением, образованием, учебой. В отличие от российских студентов, тайваньские называют в качестве определений такие, которые свидетельствуют о труде прочтения - занятии не всегда увлекательном и легком, а также о физических ха- 
рактеристиках книги: тяжелая, толстенная, серьезная, трудная. Хотя и здесь среди оценок доминирует интересная.

Для старшеклассников Китая и Монголии книга также является авторитетным источником знания, отношение к ней формируется исторической традицией и актуальными обстоятельствами учебного процесса: книга для них - это «окно мира», читающий человек «будет образованныл». Среди любимых жанров, названных респондентами данной группы, - рассказы и истории, учебная литература, журналы, книги о русской культуре, сказки, стихи, легенды, загадки. Многие школьники отмечают воспитательный характер книги: «Я люблю читать книги, которые придают сил и наставляют меня на правильный путь».

В списке читательских предпочтений российских студентов книги, выбор которых в значительной степени обусловлен школьной программой по литературе: романы М.А. Булгакова («Мастер и Маргарита» - 15\%), Л.Н. Толстого («Война и мир», «Воскресение» - 10\%), Ф.М. Достоевского («Преступление и наказание» 4\%), И.С. Тургенева («Отцы и дети» - 2\%), повести А.С. Пушкина («Капитанская дочка»), Н.В. Гоголя («Тарас Бульба»), А.И. Куприна («Олеся»). Зарубежная литература представлена именами Дж. Сэлинджера («Над пропастью во ржи»-2\%), Э.М. Ремарка (7\%), Р. Брэдбери (6\%), а также современными создателями романов в жанре научной фантастики и в стиле фэнтэзи (Б. Вербер «Империя ангелов», Д. Киз «Цветы для Элджернона», Дж.Р.Р. Мартин «Песнь льда и пламени» и т.п.).

Названия отмеченных литературных произведений свидетельствуют о том, что граница освоенного художественного пространства пролегает не только по отечественной территории - поля зарубежной словесности молодым читателям известны и дороги.

В качестве любимых героев в анкетах лидируют персонажи классических произведений, включенных в школьную программу: Маргарита, Наташа Ростова, Евгений Онегин, Татьяна Ларина, Воланд, Андрей Болконский, Пьер Безухов, Григорий Печорин, Пётр Гринев. Зарубежную литературу представляют Гарри Потер, главный герой одноименного молодежного бестселлера, Шерлок 
Холмс, детектив с уникальными дедуктивными способностями, Мартин Иден (Джек Лондон), Маленький принц (Антуан де СентЭкзюпери). Можно предположить, что популярности первых в значительной степени способствовали уроки литературы, а последних - кинематографические варианты произведений.

Некоторые респонденты не сумели дать ответа на поставленные вопросы: любимой книги не назвали 9\% опрошенных, любимого литературного героя - 24\%. Вероятно, данное обстоятельство является следствием несформировавшегося читательского вкуса и отсутствия необходимых читательских компетенций, как и самой потребности читать.

Интересный материал для размышлений дают ответы на вопрос о том, какие литературные персонажи символизируют для респондентов настоящую любовь. Дело в том, что отношения влюбленных людей, изображенные в художественной литературе, не только окрашены индивидуальными психологическими особенностями героев, но и включены в национальный культурный контекст, который определяет характер и вектор эмоциональных переживаний.

Георгий Гачев, философ и культуролог, обсуждая в книге «Русский Эрос» национальные особенности человеческих взаимоотношений, проницательно заметил, что «русская любовь между мужчиной и женщиной - той же природы, что и любовь к родине», эти чувства схожи между собой глубиной переживания и пронзительной грустью какой-то изначальной неосуществимости: «Жизнь разводит влюбленных, как мосты над Невой, - верно, для того, чтобы усиливались духовные тяготения и чтобы стягивалась из конца в конец вся необъятная Русь перекрестными симпатиями рассеянных по ней существ» [6].

Образ России ассоциируется для большинства участников опроса с непреодолимостью «русской силы» и умением человека любить без оглядки, всей душой, беззаветно и преданно. Сравнивая предложенные преподавателем размышления выдающихся мастеров слова о России, студенты выбрали в качестве наиболее созвучных своему восприятию Родины те высказывания, в которых отражена идея невероятного, немыслимого напряжения сил - фи- 
зических и духовных. Они представлены фрагментами из повести Н.В. Гоголя «Тарас Бульба» [7. С. 258]:

«Да разве найдутся на свете такие огни, муки и такая сила, которая бы пересилила русскую силу!» Н. Гоголь. «Тарас Бульба» $(59 \%)$.

«Бывали и в других землях товарищи, но таких, как в Русской земле, не было таких товарищей... Нет, братцьь, так любить, как русская душа, - любить не то чтобы умом или чем другим, а всем, чем дал бог, что ни есть в тебе, а... Нет, так любить никто не может». Н. Гоголь «Тарас Бульба» $(54 \%)$.

Именно такой силы чувство характеризует литературных персонажей, которые являются для студентов-читателей символами настоящей любви: это герои произведений А. Куприна «Гранатовый браслет» (Желтков - 13\%), М. Булгакова «Мастер и Маргарита» (Маргарита - 9\%), А. Пушкина «Евгений Онегин» (Татьяна Ларина - 9\%). Показательно, что в качестве наиболее ценимых качеств указанных героев респонденты называют способность к самопожертвованию, искренность и бескорыстность чувства, способность любить вопреки сложившимся обстоятельствам: без жертвенного подвига, с их точки зрения, нет любви.

Любовь без трагического ореола теряет свою силу и тайну, превращаясь в добрую дружбу между супругами, не способную конкурировать с истинным чувством любви ни по силе, ни по глубине, ни по драматизму. Маргарита была замужем за человеком, от которого «ничего не видела, кроме добра». Князь Шеин - благородный и тонко чувствующий спутник Веры, муж Татьяны Лариной - князь N., почтенный и заслуженный генерал, Пьер Безухов - любящий, глубоко мыслящий отец семейства, однако представление об истинной любви связано у читателей совсем с другими героями этих произведений. Именно трагическая цена, которую заплатили за право любить Г.С. Желтков, Маргарита, Андрей Болконский, Татьяна Ларина, способна убедить читателей в искренности и самоотверженности подлинного чувства.

Думается, что подобное понимание любви доказывает то особое качество национального менталитета, которое исследователи 
называют бинарным максимализмом и которое отчетливо выражено лаконичной формулой «или все, или ничего». Истинное чувство должно быть сопряжено с внутренней конфликтностью образа и требовать от личности жертвенного самоотречения, напряженного духовного устремления, высокой, часто трагической платы за любовь - не случайно «сквозь всю русскую литературу проходит высокая поэзия неосуществленной любви» [6], ибо только такая любовь может оставаться вечной и неизменной.

В русской литературе любовь понимается, прежде всего, как духовная максима, недостижимый идеал, поскольку она отражает не только реальное человеческое чувство, но и напряженность душевного порыва личности в поисках нравственного абсолюта, без которого нет счастья русской душе. Именно эта культурная установка отчетливо проявляется в отношении современных читателей к героям произведений, символизирующим для них подлинное и высокое чувство.

Способ толкования литературного произведения зависит как от сложившейся практики отношения к книге, так и от типа ее восприятия. Отечественная традиция понимания художественного текста как учебника жизни находит свое отражение в студенческих комментариях по поводу прочитанного - «учительный» характер книги отмечают многие участники опроса: «я понял, в какую сторону развиваться», «книга учит находить выход в трудных ситуациях, не сдаваться», «эта книга научила меня цеенть и уважать людей», «книга написана известным современным астронавтом, который своим примером может многому научить читателя», «книга - один из главных путеводителей в жизни».

В современных искусствоведческих исследованиях определены четыре основных типа зрителей, которые выделены на основании доминирующего мотива приобщения к искусству: это проблемно, нравственно, гедонистически и эстетически ориентированные зрители [8]. Такая типология представляется вполне приемлемой и для исследования читательской аудитории.

Анализ студенческих анкет показывает безусловное преобладание проблемно ориентированных читателей, которые ждут от ли- 
тературы, прежде всего, расширения своего жизненного опыта. Слово «проблема» является самым частотным при оценке и толковании выделенной по тому или иному основанию книги (26 упоминаний среди 100 участников опроса). Вполне вероятно, это может быть следствием работы педагогов-словесников в рамках подготовки к ЕГЭ по литературе, ориентирующих старшеклассников на выделение проблемного поля художественного произведения. Вместе с тем формулировка проблем, их характеристика зачастую носят весьма поверхностный и абстрактный характер: так, например, респондент называет в качестве любимой книги роман Л.Н. Толстого «Войну и мир» потому, что в нем «затронуты все проблемь всех времен и народов».

Этическая ориентация основана на интересе к нравственным ценностям и эталонным моделям поведения, заложенным в художественном произведении; она характеризует вторую группу читателей, которые отмечают в качестве достоинств текста умение автора показать «тонкую грань между добром и злом», сформулировать этические нормы должной жизни (книга Ремарка «Искра жизни» «научила правильно расставлять приоритеты, радоваться и иченить жизнь, стремиться к совершенству»). Следует отметить особый интерес студентов к творчеству Э.М. Ремарка: среди 100 опрошенных 12 человек выдели такие его произведения, как «Три товарища», «Триумфальная арка», «На Западном фронте без перемен», «Черный обелиск», «Ночь в Лиссабоне», «Жизнь взаймы», а Лилиан (персонаж последнего романа) была указана в качестве любимой героини. В ситуации духовной неопределенности, всегда сопровождающей социокультурные изменения в жизни общества, творчество Ремарка устанавливает для молодых читателей ту систему нравственных координат и оценок, которой им не хватает в современной общественной практике и в которой они нуждаются особенно остро, в том числе и в силу своего возраста.

Понятно и объяснимо, что эстетическое восприятие текста, требующее от читателя основательного знакомства с художественным языком и средствами его выразительности, встречается у молодых читателей нечасто и проявляется в умении выделить элементы ху- 
дожественной структуры произведения: они отмечают особенности сюжета, жанра, глубокий замысел автора, интересных для них персонажей.

Гедонистически ориентированная группа ждет от процесса чтения удовольствия, релаксации, приятного и легкого времяпрепровождения, не обремененного интеллектуальным и духовным напряжением. Такие читатели в качестве любимой книги указывают фантастику, литературу в жанре фэнтэзи или детектива (21\%), практически не объясняя причин своего выбора и не размышляя по поводу прочитанного.

Думается, можно говорить также о формировании нового читательского типа-читателя прагматичного, нацеленного на получение конкретного знания и далекого от художественной рефлексии. Разумеется, формирование данного типа обусловлено целым рядом экономических и социальных факторов, рассмотрение которых не входит в задачу настоящего исследования; однако появление читателя - прагматика важно учесть в качестве потребителя на книжном рынке.

Действительно, ответы некоторых респондентов отражают их желание получить из книг конкретные рекомендации в области развития собственных экономических (4\%) и, особенно, психологических (11\%) навыков. В этой связи в качестве любимых отмечены книги У. Айзексона («Стив Джобс»), К. Хэдфилда («Руководство астронавта по жизни на Земле»), Олега Тинькова («Я такой как все»), Ника Вуйчича («Жизнь без границ: Путь к потрясающе счастливой жизни»), Наполеона Хилла («Думай и богатей»), Н. Козлова («Как относиться к себе и к людям»), Джона Тамни («Как работает экономика») - всего 15 книг, которые помогают, по словам респондентов, «научиться любить жизнь, понять себя, эффективно использовать время, преодолевать трудности и быть счастливым человеком».

Проявил данную читательскую категорию и вопрос о книге, которую опрашиваемые взяли бы с собой на необитаемый остров. Среди самых разнообразных ответов («Произведение объемное, поэтому можно перечитывать столько, сколько захочется, каж- 
дый раз обращая внимание на разные ситуации»-о «Мастере и Маргарите», о "Преступлении и наказании» - «потому что книга еще не дочитана»), самую большую группу представляют книги практического назначения: справочники по медицине, сельскому хозяйству, пособия по выживанию в экстремальных условиях, сборники полезных растений (15\%).

Не всегда различая художественную, научно-популярную и публицистическую литературу, участники опроса часто делают выбор в пользу конкретного знания и убедительного примера, связанного с жизнью реального и известного человека. Территория художественного вымысла оказывается при этом за пределами их читательских интересов.

Подведем итоги и отметим некоторые существенные тенденции, проявившиеся в ходе проведенных опросов и социолингвистических экспериментов.

В перечне прочитанных книг практически отсутствуют произведения современных российских писателей: в школе им уделяется мало внимания, а иного источника знания о новинках отечественной литературы у читателей сегодня нет, что связано с исчезновением «фигур литературно-коммуникативных посредников», призванных подчеркивать значимость того или иного литературного события и открывать для широкой публики новые имена. По мысли Б. Дубина, это свидетельствует «об отмирании символического значения самой подобной функции, самого такого знания, авторитетности подобной роли», которая раньше подкреплялась высоким престижем литературы в качестве проекта национальной культуры [9].

Справедливости ради заметим, что сегодня существуют национальные литературные премии, устраиваются книжные выставки, возникают интернет-порталы, предназначенные для расширения кругозора и развития читательских компетенций заинтересованной публики, однако согласимся, что аудитория этих реальных и виртуальных событий массовой не является.

Тем не менее чтение по-прежнему является престижным занятием в глазах большинства молодых людей, обучающихся в вузах, 
а книга зачастую воспринимается ими как нравственный путеводитель на собственном жизненном пути. Важную роль в становлении читательских компетенций молодежи играет средняя школа, которая продолжает выполнять функцию формирования корпуса авторитетных художественных текстов, актуальных для общественного сознания и определяющих смысловое содержание культурного кода нации.

\section{Лumepamypa}

1. Дубин Б.В. Хартия книги: книга и архикнига в организации и динамике культуры // Дубин Б.В. Слово - письмо - литература : Очерки по социологии современной культуры. М. : Новое литературное обозрение, 2001. URL: https://www.e-reading.club/book.php?book=1019687

2. Хазагеров Г. Персоносфера русской культуры // Новый мир. 2002. № 1. URL: ttp://magazines.russ.ru/novyi_mi/2002/1/hazag.html

3. Дубин Б.В. «Литературное сегодня»: взгляд социолога // Дубин Б.В. Слово - письмо - литература : Очерки по социологии современной культуры. М.: Новое литературное обозрение, 2001. URL: https://www.e-reading.club/ book.php?book=1019687

4. Баренбаум И.Е. Читатель: VI глава из книги «Основы книговедения» // История русского читателя. Вып. 5 : сб. ст. // ред.-сост. П.Н. Базанов, В.В. Головин. СПб. : Изд-во СПбГУКИ, 2010. С. 230-246.

5. Морозова М.С. Отражение изменений социального портрета жителя СанктПетербурга в читательских и покупательских предпочтениях // История русского читателя. Вып. 5 : сб. ст. / ред.-сост. П.Н. Базанов, В.В. Головин. СПб.: Изд-во СПбГУКИ, 2010. С. 163-166.

6. Гачев Г. Русский эрос. Роман «Мысли» с «Жизнью». М. : Интерпринт, 1994. URL: http://philologos.narod.ru/texts/gachev-eros.htm

7. Гоголь Н.В. Тарас Бульба // Гоголь Н.В. Избранное. М. : Просвещение, 1986. С. $195-295$.

8. Кривцун О.А. Психология художественного восприятия / Кривцун О.А. Эстетика : учеб. М. : Аспект-Пресс, 2003. С. 333-343.

9. Дубин Б.В. Уход читателей // Дубин Б.В. Слово - письмо - литература : Очерки по социологии современной культуры. М. : Новое литературное обозрение, 2001. URL: https://www.e-reading.club/book.php?book=1019687 


\section{THE BOOK AS A SPACE OF IMAGES AND MEANINGS: THE RANGE OF YOUNG STUDENTS' READING PREFERENCES}

Tekst. Kniga. Knigoizdanie - Text. Book. Publishing, 2018, 16, pp. 72-85

DOI: $10.17223 / 23062061 / 16 / 5$

Natalya V. Oturgasheva, Siberian Institute of Management, Branch of the Russian Academy of National Economy and Public Administration under the President of the Russian Federation (Novosibirsk, Russian Federation). E-mail: vialuna@list.ru

Keywords: sociolinguistic experiment, linguo-cultural concept, book, reader's perception.

The article presents the results of surveys and socio-linguistic experiments carried out by the author in 2015-2017 among Russian and Taiwanese students as well as among Chinese and Mongolian school children. The article aims to identify the attitude of modern youth towards the linguo-cultural concept 'book', to determine the range of significant fiction books for young people and types of readers' perception, assessment of the book's role in the formation of students' youth personal sphere.

A book is generated by the epoch, literary plots and characters are engendered within the inmost recesses of their time and open up to the reader within the context of certain socio-cultural circumstances; therefore, the popularity of a book is often determined by the nature of those circumstances and by the fact to what extent the book's content responds to spiritual needs of its readers.

Despite the fact that nowadays books have been sidelined by other leisure activities - TV and Internet in the first place - they still retain high significance and immediacy: $94 \%$ of respondents consider reading as a necessity for the people of today. The book in the consciousness of the Russian students is closely connected with the field of knowledge, educational space where they exist. For the Taiwanese students and high schoolers of China and Mongolia the book is also an authoritative source of knowledge, the attitude towards it is shaped up by the historical tradition and present-day circumstances of the teaching and learning process.

The way a literary work is interpreted depends on both the common practice of the attitude toward the book and the way it is perceived. The national tradition of the literary text understanding as a life lesson is reflected in modern students' questionnaires many respondents note the 'instructive' nature of the book.

Students' questionnaires analysis shows the ultimate majority of problem-oriented readers who above all expect broadening their life experience from literature. Ethical orientation is based on the interest in the moral values and reference models of behaviour behind a literary work. Aesthetic appreciation of the text that requires profound acquaintance with the literary language and expressive means on part of the reader is quite rare and is manifested in the ability to identify literary components in the text. The group with a hedonistic approach expects pleasure, relaxation, nice and easy pastime not burdened with intellectual and spiritual efforts from the process of reading.

It is time to speak about the formation of a new reader's type - a pragmatic reader aimed at obtaining specific knowledge and far from artistic reflection. 
Analysis of students' questionnaires shows that the list of books read lacks pieces of modern Russian writers: very little attention is paid to them at schools, and readers have no access to other sources concerning novelties of national literature.

Reading is still a prestigious activity in the eyes of most young people who study at universities, and they pften perceive the book as a kind of a moral guide in their life journey. Secondary school plays an important role in developing reading competencies of the youth. It keeps on performing the function of building up the set of authoritative literary texts, which are essential for public conscience and define the semantic content of the national culture code.

\section{References}

1. Dubin, B.V. (2001a) Slovo - pis'mo - literatura: Ocherki po sotsiologii sovremennoy kul'tury [Word - Letter - Literature: Essays on the Sociology of Contemporary Culture]. Moscow: Novoe literaturnoe obozrenie. [Online] Available from: https://www.e-reading.club/book.php?book=1019687.

2. Khazagerov, G. (2002) Personosfera russkoy kul'tury [Perssonosphere of Russian culture]. Novyy mir. 1. [Online] Available from: ttp://magazines.russ.ru/novyi_mi/2002/1/hazag.html.

3. Dubin, B.V. (2001b) Slovo - pis'mo - literatura: Ocherki po sotsiologii sovremennoy kul'tury [Word - Letter - Literature: Essays on the Sociology of Contemporary Culture]. Moscow: Novoe literaturnoe obozrenie. [Online] Available from: https://www.e-reading.club/book.php?book=1019687.

4. Barenbaum, I.E. (2010) Chitatel': VI glava iz knigi "Osnovy knigovedeniya" [The Reader: Chapter 6 from "Fundamentals of Bibliology"]. In: Bazanov, P.N. \& Golovin, V.V. (eds) Istoriya russkogo chitatelya [History of the Russian reader]. Issue 5. St. Petersburg: St. Petersburg State University of Culture and Arts. pp. 230-246.

5. Morozova, M.S. (2010) Otrazhenie izmeneniy sotsial'nogo portreta zhitelya Sankt-Peterburga $\mathrm{v}$ chitatel'skikh i pokupatel'skikh predpochteniyakh [Reflection of changes in the social portrait of St. Petersburg resident in reading and buying preferences]. In: Bazanov, P.N. \& Golovin, V.V. (eds) Istoriya russkogo chitatelya [History of the Russian reader]. Issue 5. St. Petersburg: St. Petersburg State University of Culture and Arts. pp. 163-166.

6. Gachev, G. (1994) Russkiy eros. Roman "Mysli” s "Zhizn'yu” [Russian Eros. The novel of "Thought" with "Life"]. Moscow: Interprint. [Online] Available from: http://philologos.narod.ru/texts/gachev-eros.htm.

7. Gogol, N.V. (1986) Izbrannoe [Selected Works]. Moscow: Prosveshchenie. pp.195-295.

8. Krivtsun, O.A. (2003) Estetika [Aesthetics]. Moscow: Aspekt Press. pp. 333-343.

9. Dubin, B.V. (2001c) Slovo - pis'mo - literatura: Ocherki po sotsiologii sovremennoy kul'tury [Word - Letter - Literature: Essays on the Sociology of Contemporary Culture]. Moscow: Novoe literaturnoe obozrenie. [Online] Available from: https://www.e-reading.club/book.php?book=1019687. 